\title{
Building Emotional Competence in Educators
}

\author{
Jonathan Kasler ${ }^{1}$, Meirav Hen ${ }^{1} \&$ Adi Sharabi Nov ${ }^{2}$ \\ ${ }^{1}$ Senior Lecturer in Education Department, Tel Hai College Israel, Israel \\ ${ }^{2}$ Lecturer in Education Department, Tel Hai College Israel, Israel \\ Correspondence: Jonathan Kasler, Senior Lecturer in Education Department, Tel Hai College Israel, Israel. E-mail: \\ Kasler.Jon@gmail.com \\ Received: August 25, 2013 \\ Accepted: September 23, 2013 \\ Online Published: September 26, 2013 \\ doi:10.5430/ijhe.v2n4p31 \\ URL: http://dx.doi.org/10.5430/ijhe.v2n4p31
}

\begin{abstract}
The importance of emotion in the process of learning interpersonal communication in educational settings has been well documented. We administered the Schutte Self-Report Emotional Intelligence Test (Schutte et.al., 1998), the Interpersonal Reactivity Index (Davis, 1980), and the Emotional Self-Efficacy Scale (Kirk et al., 2008) to 50 undergraduate education students who were enrolled in an elective course on emotional intelligence in education, at commencement and at the end of the course. Results showed an increase in emotional self-efficacy and emotional intelligence, but no increase in empathy. These results support the view that social emotional competence can be enhanced within an academic learning environment, thus providing students of education and perhaps other people-oriented professions with valuable preparation for future careers.
\end{abstract}

Keywords: Emotional intelligence, Emotional self-efficacy, Empathy, Higher education

\section{Introduction}

In an age of competition among people with academic qualifications, individuals need to utilize their personal qualities. Brown, Hesketh, and Williams (2002) coined the term "inflation of credentials" to describe the uncertain situation of graduates today, who inevitably ask themselves how they can attain a competitive edge over others similarly qualified. Archer and Davison (2008) surveyed employers regarding the skills they sought among potential employees. While literacy and numeracy were seen as crucial, skills such as initiative, self-management, interpersonal communication, and teamwork also appeared to top the lists for many employers. Thus the question arises whether institutions of higher education do or should facilitate the development of these skills while also maintaining their focus on the traditional role of striving for academic excellence.

Over the last decade, a growing body of research has supported the contribution of emotional intelligence (EI) to health professionals' knowledge and practice, patient outcomes, and educational and professional success (Mayer, Roberts, \& Barsade, 2008). EI refers to the ability to process emotional information as it pertains to the perception, assimilation, expression, regulation, and management of emotion (Brackett, Rivers, Shiffman, Lerner, \& Salovey, 2006) . It involves a set of mental abilities with which individuals employ high-level processes regarding their attitudes to feelings, clarity of feelings, ability to discriminate among feelings, and mood-regulating strategies (Brackett \& Mayers, 2003). It is the ability to carry out accurate reasoning about emotions and the ability to use emotions and emotional knowledge to enhance thought (Lopes, Salovey, Côte, \& Beers, 2005). A meta-analysis of research conducted with 59 samples of participants found that higher EI was associated with a variety of better outcomes, including employment and academic performance (Boyatzis, 2006; Daus \& Ashkanasy, 2005).

Despite the growing evidence of the effectiveness of EI, few curricula of higher education programs adequately address the development of EI as a means to enhance the intrapersonal and interpersonal capabilities of their students ( Low \& Nelson, 2005).

Elias (2009) summarized the essential social emotional competencies, often called emotional intelligence, based on extensive research conducted under the aegis of the Collaborative for Academic, Social and Emotional Learning (see www.casel.org):

- knowing and managing one's emotions;

- listening and communicating carefully and accurately; 
- recognizing strengths in self and others;

- showing ethical and social responsibility;

- greeting, approaching, and conversing with diverse others;

- taking others' perspectives;

- perceiving others' feelings accurately;

- respecting others;

- setting adaptive goals;

- solving problems and making decisions effectively;

- cooperating;

- leading and also being an effective team member;

- negotiating and managing conflicts peacefully;

- building constructive, mutual, and ethical relationships; and

- seeking and giving help.

These skills are seen as essential to success in life, in general, and in sustaining progress in the world of work, in particular (Goleman, 1995).

Recent research has studied the impact of courses that promote emotional intelligence in training settings (Clark, Callister, \& Wallace., 2003). Daniel Goleman's (1995) groundbreaking book, Emotional Intelligence, has stimulated increasing interest in the role of emotional intelligence (EI) in workplace settings, leading to the production of a body of research on the efficacy of training programs of various kinds (Cherniss, Goleman, Emmerling, Cowan, \& Adler, 1998). Most such studies have been conducted in business schools, focusing on the evaluation of short-term interventions with very small samples. The majority indicated significant positive changes in EI; however, there is an absence of high-quality empirical evidence regarding the efficacy of these interventions (McEnrue, Groves, \& Shen, 2010).

In a study of the effects of EI instruction on the academic achievements of 31 graduate students of management, Jaeger (2003) reported notable gains in emotional intelligence between the start and completion of the course. Furthermore, the levels of EI correlated positively with academic achievement as measured by final project grades.

Low and Nelson (2005) argued that in order to develop students' emotional skills, EI education models should include practice, experience-based methods, and evaluation. On the basis of these principles, they developed and tested an EI education model for teachers and students predicated upon transformative learning. Their model, which defines emotional intelligence as a learned capacity to identify, understand, experience, and express human emotions in healthy and productive ways, involves five steps (explore self-assessment, identify self-awareness, understand self-knowledge, learn self-development, and apply self-improvement), which are developed through intentional, active, and engaging processes. Their findings suggested that students who completed the EI project attained significantly higher GPAs, and academic achievement and student retention were also improved.

Weis and Arnesen (2007) experimented with an EI teaching model that integrated theoretical and experiential teaching modes. They began by defining the primary components of emotional intelligence and demonstrating the importance of these skills to academic and professional performance. Next, the participants conducted a self-critique of their own EI attributes and the authors investigated the sources of participants' "hard-wired" personal patterns, and offered "executive" coaching, as an avenue to augment EI. In their mixed model, Weis and Arnesen used interactive group exercises; explored useful coaching skills, effective communication, and listening skills with students; employed structured feedback exercises to strengthen student awareness; and concluded with the development of an action plan based upon an enhanced awareness of EI challenges that evolved from the students' experiences during the entire course. In a study of the implementation of a similar model in the training of social workers, Hen (2010) demonstrated a significant increase in EI levels, but without improvement in empathy. Walter and Hen (2009) investigated the development of EI in education students participating in a special movement course. The findings confirmed the hypotheses that engaging in special movement routines based on the Mayer \& Salovey's (1997) EI four-branch model would enhance the students' EI and allow them to improve their own learning experience.

Researchers have argued the case for teaching EI, based on the premise that people who are able to deal capably with their own feelings will be able to deal with those of others confidently, competently, and safely (Low \& Nelson, 
2005). Louie, Coverdale, and Roberts, (2006) suggested that the teaching of emotional skills might require an environment that values and exemplifies these skills. Similarly, Danielsen, and Cawley (2007) concluded that the best way to teach compassion, integrity, and other emotional capacities to health care professionals is by modeling these values to the students. Researchers and practitioners of fostering EI and social emotional skills have contributed to the development of appropriate programs for training educators. For example, several researchers have suggested models or programs for enhancing the emotional intelligence of teachers with the aim of maximizing the potential of their students. In their review of the Emotionally Intelligent Teacher Workshop, Brackett and Kataluk (2006) concluded that emotionally intelligent teachers are better able than others to create a secure, caring, satisfying, as well as creative and dynamic school environment. Low, Nelson, Stottlemyer, and Davenport (2000) found that their model, designed to promote emotional intelligence among teachers, resulted in improved achievements among the students of the participating teachers. Similarly, in an evaluation of the Incredible Years programs, which combined both teacher and child training with a strong focus on emotional competencies, Webster-Stratton and Reid (2011) and Webster-Stratton, Reid, and Stoolmiller (2008) reported on the success of these programs in improving outcomes for teachers as well as disadvantaged children.

Ergur (2009) concluded that all educational professionals must engage in formal comprehensive courses to develop their own emotional intelligence and use it to provide an empathic learning environment for their students. We suggest that such models and programs may provide appropriate avenues for promoting emotional intelligence among students in higher education who are increasingly expected to demonstrate people skills in an ever widening variety of careers.

\subsection{The Present Study}

Based on the literature cited, we developed a 30-hour SEL course, entitled Emotional Intelligence in Education, for undergraduate students of education. Most of the students were freshmen and the course provided them with a first opportunity to become familiar with the principles of social emotional learning. During the course, the students learned key concepts of emotional intelligence and their understanding was deepened by a significant component of experiential learning, specifically designed to embed experiential learning within a traditional academic framework.

At the beginning of one lesson, one of the authors gave the students a piece of paper with the outline of a "mandala circle" (used in this case to provide a framework for focusing the individual's attention on positive self-evaluation) and asked them to fill it in. When they finished, he asked them to reflect on the personal significance of this task for them and to come to the next class next ready to talk about it. Those students who came to class having completed the assignment smiled with understanding when he introduced the subject of self-awareness as the cornerstone of all social emotional competencies. In the pursuant class discussion, their contributions were strikingly personal and it seemed clear that the topic was meaningful to them. As the course progressed, the instructor assigned the students a series of similar tasks designed to encourage thinking, feeling, and reflecting about their own competencies, with the goal of promoting personal involvement in the learning process using the four-branch model of emotional intelligence (Mayer \& Salovey, 1997).

Task 1. Perception and expression of emotion: Compose a journal of the coming week and write down dominant emotions for each day.

Task 2. Emotional facilitation: Discuss how one might use positive emotion to alter a negative, narrow-minded interpretation of what appears to be negative behavior of another driver on the road.

Task 3. Emotional understanding: Discuss the consequences of emotions in examples of one's personal behavior and reactions to a recent event.

Task 4. Emotional management: Using examples from personal experience, discuss how people handle emotional states, if and when they have serious personal problems or need to negotiate stressful situations.

In the process of these assignments and the class discussions, a possible avenue for personal development was opened. The present research investigated the impact of studying social emotional competences (SEC) on students in higher education when a significant component of experiential learning with the specific goal of enhancing SEC was embedded in the course. We hypothesized that there would be an increase in levels of emotional intelligence, empathy, and emotional self-efficacy from the beginning to the end of course for those students who participated (the intervention group), and that no change would be found in the control group (students who did not take such a course). In addition, we hypothesized that there would be positive relationships among the different subscales of emotional intelligence, empathy, and emotional self-efficacy, with the exception of the personal distress subscale, which we expected to correlate negatively with all the other subscales. 


\section{Method}

\subsection{Sample and Procedure}

The researchers distributed questionnaires to 76 undergraduate students in the education department at a college in northern Israel. The majority of students (50) were enrolled in a semester-long course, Emotional Intelligence in Education, which is offered as an elective in the first or second year of BA studies in education. They comprised the intervention group. The remaining 26 students were not enrolled in, and had not previously taken this course; they served as a control group. All the intervention group participants completed the questionnaires voluntarily and anonymously during class time, in the first and the last session of the 14-week course. The control group participants were first- and second-year education students who did not take this course, and voluntarily completed the questionnaires at roughly the same (during Week 1 and Week 14 of the semester). The majority of the participants $(94.4 \%)$ were women and $5.6 \%$ were men, with a mean age of $25.6(S D=6.3) ; 49.3 \%$ of students were in their first year of undergraduate study and 50.6 were in their second year.

\subsection{Instruments}

For the purpose of the current study, we used three instruments. The Interpersonal Reactivity Index (IRI) for measuring empathy was administered to all the research participants; the Schutte Self-Report Emotional Intelligence Test (SSREIT) and the Emotional Self-Efficacy Scale (ESES) were administered to the intervention group only. IRI (Davis, 1980) was designed for the purpose of measuring empathy. It includes 28 items and is scored on a 5-point Likert scale, from 1 (does not describe me well) to 5 (describes me very well). It is composed of four subscales (7 items for each subscale): (a) fantasy, composed of items such as "I really get involved with the feelings of the characters in a novel"; (b) empathic concern, composed of items such as "When I see someone being taken advantage of, I feel kind of protective towards them"; (c) perspective taking, composed of items such as "Before criticizing somebody, I try to imagine how I would feel if I were in their place"; and (d) personal distress, composed of items such as "I tend to lose control during emergencies".

The IRI subscales have been documented to have satisfactory internal reliabilities (ranging from $\alpha=.71$ to $\alpha=.77$ ) and test-retest reliabilities (ranging from $\alpha=.62$ to $\alpha=.80$ ). In our study, the internal reliability of the IRI subscales ranged from $\alpha=.69$ to $\alpha=.87$.

The Schutte Self-Report Emotional Intelligence Test (SSREIT) (Schutte et al., 1998) is a trait measure of emotional intelligence based on Salovey and Mayer's (1990) model of emotional intelligence. The scale consists of 33 items designed to measure the extent to which the respondent typically appraises emotions in the self and others, understands emotions in the self and others, regulates emotions in the self and others, and utilizes emotions to solve problems.

It includes the following subscales: (a) appraisal and expression of emotions (13 items), such as "I like to share my emotions with others"; (b) regulation of emotions (10 items), such as "I have control over my emotions"; and (c) utilization of emotions (10 items), such as "When I am in a positive mood, solving problems is easy for me". These subscales were found reliable, with a Cronbach's Alpha ranging between 0.78 and 0.88 .

The measure has exhibited good internal consistency, with a Cronbach's alpha for the total scale ranging from .87 to .90 across several samples (Schutte et al., 1998). Two-week test-retest reliability for the measure was .78, and concurrent, predictive, and discriminant validity were indicated (Schutte et al., 1998). In the present sample, $\alpha=.93$.

The Emotional Self-Efficacy Scale (ESES) is a 32-item self-report measure of emotional self-efficacy developed by Kirk et al. (2008). It is based on Mayer and Salovey's (1997) and Mayer et al.'s (2004) four-branch model of emotional intelligence, which presents a conceptually and empirically well-grounded description of adaptive emotional functioning, and Bandura's (2001) specific guidelines for assessment of self-efficacy in a given realm. It has four subscales (with 8 items for each subscale): (a) perception of emotions; (b) using emotions; (c) understanding emotions; and (d) management of emotions. The items are scored on a Likert scale ranging from 1 (does not describe me well) to 5 (describes me very well). In the validations sample, the internal consistency reliabilities of ESES as an eight-factor scale ranged from .87 to .90 , and a test-retest reliability coefficient of .78 was computed (Kirk et al., 2008). In the present sample, the reliability of the scale was $\alpha=.94$.

ESES is a relatively new scale, and was used in this research with the intervention group ESES, mainly to validate the results of SSREIT. 


\section{Findings}

In order to examine the possibility of significant differences in initial emotional intelligence and empathy levels of the intervention and control groups, we compared the results of the two samples at the beginning of the semester (IRI $\mathrm{F}_{(4,71)}=12.001, \mathrm{p}<.001, \mathrm{Eta}^{2}=0.403$, SSREIT $\left._{(3,72)}=16.435, \mathrm{p}<.001, \mathrm{Eta}^{2}=0.406\right)$ (see table 1).

Table 1. Beginning-of-semester means, standard deviations and MANOVA: IRI and SSREIT

\begin{tabular}{lccccccc}
\hline & \multicolumn{2}{c}{$\begin{array}{c}\text { Control group } \\
(\mathrm{n}=26)\end{array}$} & \multicolumn{2}{c}{$\begin{array}{c}\text { Intervention group } \\
(\mathrm{n}=50)\end{array}$} & & & \\
\cline { 2 - 5 } Factor & $\mathrm{M}$ & $\mathrm{SD}$ & $\mathrm{M}$ & $\mathrm{SD}$ & $\mathrm{F}_{(1,74)}$ & $\mathrm{p}$ & Eta $^{2}$ \\
\hline IRI & 25.08 & 6.01 & 23.74 & 6.53 & 0.756 & 0.387 & 0.010 \\
Fantasy & 30.81 & 2.95 & 28.90 & 4.67 & 3.586 & 0.062 & 0.046 \\
Empathic concern & 27.35 & 4.60 & 21.08 & 3.32 & 46.555 & 0.000 & 0.386 \\
Perspective taking & 19.39 & 5.08 & 20.66 & 4.39 & 1.297 & 0.258 & 0.017 \\
Personal distress & & & & & & & \\
SSREIT & 51.54 & 7.00 & 52.58 & 6.53 & 0.415 & 0.522 & 0.006 \\
Expression of emotions & 38.54 & 4.77 & 37.26 & 5.41 & 1.034 & 0.312 & 0.014 \\
Regulation of emotions & 38.65 & 4.60 & 33.82 & 5.02 & 16.793 & 0.000 & 0.185 \\
Utilization of emotions & 128.73 & 13.46 & 123.66 & 15.75 & 1.951 & 0.167 & 0.026 \\
Overall emotional intelligence & & & & & & & \\
\end{tabular}

The comparisons revealed a significant initial difference between the groups in one IRI subscale - perspective taking - and one SSREIT subscale - utilization of emotions. Interestingly, in the two subscales, the scores of the control group were higher than those of the intervention group.

In order to examine differences in the emotional intelligence and empathy levels between the intervention and control groups at the end of the semester (post-test), we compared (IRI $F_{(4,71)}=6.571, p<.001$, Eta $^{2}=0.270$, SSREIT $\left.\mathrm{F}_{(3,72)}=17.354, \mathrm{p}<.001, \mathrm{Eta}^{2}=0.420\right)($ see table 2$)$.

Table 2. End-of-semester means, standard deviations and MANOVA: IRI and SSREIT

\begin{tabular}{|c|c|c|c|c|c|c|c|}
\hline \multirow[b]{2}{*}{ Factor } & \multicolumn{2}{|c|}{$\begin{array}{l}\text { Control group } \\
(\mathrm{n}=26)\end{array}$} & \multicolumn{2}{|c|}{$\begin{array}{l}\text { Intervention group } \\
(\mathrm{n}=50)\end{array}$} & \multirow[b]{2}{*}{$\mathrm{F}_{(1,74)}$} & \multirow[b]{2}{*}{$\mathrm{p}$} & \multirow[b]{2}{*}{$\mathrm{Eta}^{2}$} \\
\hline & M & $\mathrm{SD}$ & $\mathrm{M}$ & SD & & & \\
\hline \multicolumn{8}{|l|}{ IRI } \\
\hline Fantasy & 24.12 & 4.78 & 24.00 & 6.00 & 0.007 & 0.932 & 0.000 \\
\hline Empathic concern & 30.42 & 2.83 & 29.20 & 3.50 & 2.366 & 0.128 & 0.031 \\
\hline Perspective taking & 26.50 & 4.65 & 21.70 & 3.48 & 25.695 & 0.000 & 0.258 \\
\hline Personal distress & 19.31 & 3.74 & 19.18 & 4.42 & 0.016 & 0.900 & 0.000 \\
\hline \multicolumn{8}{|l|}{ SSREIT } \\
\hline Expression of emotions & 51.50 & 7.06 & 54.30 & 5.46 & 3.663 & 0.059 & 0.047 \\
\hline Regulation of emotions & 37.81 & 3.69 & 39.14 & 5.77 & 1.139 & 0.289 & 0.015 \\
\hline Utilization of emotions & 38.35 & 4.22 & 35.24 & 4.80 & 7.754 & 0.007 & 0.095 \\
\hline Overall emotional intelligence & 127.65 & 11.97 & 128.68 & 15.20 & 0.089 & 0.766 & 0.001 \\
\hline
\end{tabular}

At the end of the semester, the control group still scored significantly higher than the intervention group on perspective taking and utilization of emotions.

We calculated the differences in each participant's individual scores at the beginning and end of the semester. The differences in means between the two measurement points (beginning and end of the semester) were calculated for both groups ( $\operatorname{IRI~F}_{(4,71)}=2.609, \mathrm{p}<.05, \operatorname{Eta}^{2}=0.128, \operatorname{SSREIT~}_{(3,72)}=3.731, \mathrm{p}<.05, \mathrm{Eta}^{2}=0.135$ ) (see table 3 ). 
Table 3. Group differences of means, standard deviations and MANOVA: IRI and SSREIT

\begin{tabular}{lcccccccc}
\hline \multirow{2}{*}{ Factor } & \multicolumn{7}{c}{ Control group } & \multicolumn{2}{l}{ Intervention group } & & & \\
\cline { 2 - 5 } & $\mathrm{M}$ & $\mathrm{SD}$ & $\mathrm{M}$ & $\mathrm{SD}$ & $\mathrm{F}_{(1,74)}$ & $\mathrm{p}$ & Eta $^{2}$ \\
\hline IRI & -0.96 & 4.55 & 0.26 & 4.61 & 1.213 & 0.274 & 0.016 \\
Fantasy & -0.38 & 1.81 & 0.30 & 4.06 & 0.668 & 0.417 & 0.009 \\
Empathic concern & -0.85 & 3.04 & 0.62 & 2.61 & 4.814 & 0.031 & 0.061 \\
Perspective taking & -0.08 & 3.53 & -1.48 & 2.64 & 3.820 & 0.050 & 0.049 \\
Personal distress & & & & & & & \\
SSREIT & -0.04 & 4.54 & 1.72 & 4.58 & 2.540 & 0.115 & 0.033 \\
Expression of emotions & -0.73 & 3.00 & 1.88 & 3.40 & 10.888 & 0.001 & 0.128 \\
Regulation of emotions & -0.31 & 2.66 & 1.42 & 3.66 & 4.532 & 0.037 & 0.058 \\
Utilization of emotions & -1.08 & 7.74 & 5.02 & 9.24 & 8.280 & 0.005 & 0.101 \\
Overall emotional intelligence & & & & & & & & \\
\hline
\end{tabular}

The results indicate two interesting findings. First, the scores of almost all the subscales increased (personal distress decreased) in the intervention group, but all subscales in the control group were lower at the end of course compared with the beginning. Second, a significant difference between the intervention and control groups was recorded in the degree of change in the IRI subscale of perspective taking (subscale of IRI) and in the SSREIT subscales of regulation of emotions, utilization of emotions, and overall emotional intelligence.

In order to compare the interrelationships among the subscales of emotional intelligence (the SSREIT scale), empathy (the IRI scale), and emotional self-efficacy (the ESES scale) in the intervention group at the beginning and at the end of the course, we calculated Pearson correlation coefficients (see tables 4 and 5).

Table 4. Beginning-of-semester Pearson correlations among all factors

\begin{tabular}{|c|c|c|c|c|c|c|c|c|c|c|c|c|c|}
\hline & & 1 & 2 & 3 & 4 & 5 & 6 & 7 & 8 & 9 & 10 & 11 & 12 \\
\hline 1 & $\begin{array}{l}\text { Understanding } \\
\text { emotions }\end{array}$ & - & & & & & & & & & & & \\
\hline 2 & $\begin{array}{l}\text { Perceiving } \\
\text { emotions }\end{array}$ & $0.843^{* * *}$ & - & & & & & & & & & & \\
\hline 3 & $\begin{array}{l}\text { Using } \\
\text { emotions }\end{array}$ & $0.585^{* * *}$ & $0.652^{* * *}$ & - & & & & & & & & & \\
\hline 4 & $\begin{array}{l}\text { Management } \\
\text { of emotions }\end{array}$ & $0.676^{* * *}$ & $0.712^{* * *}$ & $0.834^{* * *}$ & - & & & & & & & & \\
\hline 5 & $\begin{array}{l}\text { Emotional } \\
\text { self-efficacy }\end{array}$ & $0.840^{* * *}$ & $0.871^{* * *}$ & $0.888^{* * *}$ & $0.937^{* * *}$ & - & & & & & & & \\
\hline 6 & Fantasy & $0.309^{*}$ & 0.214 & $0.433^{* *}$ & $0.457^{* * *}$ & $0.420^{* * *}$ & - & & & & & & \\
\hline 7 & $\begin{array}{l}\text { Empathic } \\
\text { concern }\end{array}$ & $0.577^{* * *}$ & $0.474^{* * *}$ & $0.362^{* *}$ & $0.500^{* * *}$ & $0.532^{* * * *}$ & $0.655^{* * *}$ & - & & & & & \\
\hline 8 & $\begin{array}{l}\text { Perspectivetaki } \\
\text { ng }\end{array}$ & 0.242 & 0.218 & 0.192 & $0.357^{*}$ & $0.296^{*}$ & $0.260^{*}$ & $0.345^{* *}$ & - & & & & \\
\hline 9 & $\begin{array}{l}\text { Personal } \\
\text { distress }\end{array}$ & $-0.291^{*}$ & -0.146 & -0.235 & -0.184 & -0.238 & $0.274^{*}$ & 0.134 & $-0.321^{* *}$ & - & & & \\
\hline 10 & $\begin{array}{l}\text { Expression of } \\
\text { emotions }\end{array}$ & $0.743^{* * *}$ & $0.735^{* * *}$ & $0.533^{* * *}$ & $0.651^{* * *}$ & $0.734^{* * *}$ & $0.422^{* * *}$ & $0.543^{* * *}$ & $0.227^{*}$ & -0.122 & - & & \\
\hline 11 & $\begin{array}{l}\text { Regulation of } \\
\text { emotions }\end{array}$ & $0.653^{* * *}$ & $0.646^{* * *}$ & $0.801^{* * *}$ & $0.902^{* * *}$ & $0.870^{* * *}$ & $0.338^{* *}$ & $0.541^{* * *}$ & $0.324^{* *}$ & -0.173 & $0.611^{* * * *}$ & - & \\
\hline 12 & $\begin{array}{l}\text { Utilization of } \\
\text { emotions }\end{array}$ & $0.585^{* * *}$ & $0.544^{* * *}$ & $0.696^{* * *}$ & $0.747^{* * *}$ & $0.742^{* * *}$ & $0.350^{* *}$ & $0.483^{* * *}$ & $0.504^{* * *}$ & $-0.299^{* *}$ & $0.616^{* * *}$ & $0.746^{* * *}$ & - \\
\hline 13 & $\begin{array}{l}\text { Emotional } \\
\text { intelligence }\end{array}$ & $0.719^{* * *}$ & $0.700^{* * *}$ & $0.718^{* * *}$ & $0.818^{* * *}$ & $0.840^{* * *}$ & $0.427^{* * *}$ & $0.597^{* * *}$ & $0.391^{* * *}$ & -0.220 & $0.870^{* * *}$ & $0.848^{* * *}$ & $0.884^{* * *}$ \\
\hline
\end{tabular}


Table 5. End-of-semester Pearson correlations among all factors

\begin{tabular}{|c|c|c|c|c|c|c|c|c|c|c|c|c|c|}
\hline & & 1 & 2 & 3 & 4 & 5 & 6 & 7 & 8 & 9 & 10 & 11 & 12 \\
\hline 1 & Understanding emotions & - & & & & & & & & & & & \\
\hline 2 & Perceiving emotions & $0.723^{* * *}$ & - & & & & & & & & & & \\
\hline 3 & Using emotions & $0.750^{* * *}$ & $0.530^{* * *}$ & - & & & & & & & & & \\
\hline 4 & Management of emotions & $0.854^{* * * * *}$ & $0.663^{* * *}$ & $0.865^{* * * *}$ & - & & & & & & & & \\
\hline 5 & Emotional self-efficacy & $0.908^{* * *}$ & $0.738^{* * *}$ & $0.925^{* * *}$ & $0.969^{* * * *}$ & - & & & & & & & \\
\hline 6 & Fantasy & $0.352^{*}$ & 0.175 & $0.448^{* * *}$ & $0.377^{* *}$ & $0.405^{* *}$ & - & & & & & & \\
\hline 7 & Empathic concern & 0.222 & $0.352^{*}$ & $0.342^{*}$ & 0.226 & $0.306^{*}$ & 0.164 & - & & & & & \\
\hline 8 & Perspectivetaking & $0.381^{* *}$ & 0.229 & $0.413^{* *}$ & $0.566^{* * *}$ & $0.480^{* * *}$ & -0.022 & $0.295^{* *}$ & - & & & & \\
\hline 9 & Personal distress & -0.190 & $-0.499^{* * *}$ & -0.204 & -0.145 & -0.239 & $0.372^{* * *}$ & -0.136 & -0.169 & - & & & \\
\hline 10 & Expression of emotions & $0.721^{* * *}$ & $0.686^{* * *}$ & $0.781^{* * *}$ & $0.766^{* * *}$ & $0.823^{* * *}$ & $0.420^{* * *}$ & $0.240^{*}$ & 0.109 & -0.173 & - & & \\
\hline 11 & Regulation of emotions & $0.765^{* * *}$ & $0.608^{* * *}$ & $0.879^{* * *}$ & $0.868^{* * *}$ & $0.896^{* * *}$ & 0.121 & 0.204 & 0.188 & $-0.242^{*}$ & $0.659^{* * *}$ & - & \\
\hline 12 & Utilization of emotions & $0.744^{* * *}$ & $0.596^{* * *}$ & $0.890^{* * *}$ & $0.836^{* * *}$ & $0.882^{* * *}$ & $0.277^{*}$ & $0.445^{* * *}$ & $0.513^{* * *}$ & $-0.241^{*}$ & $0.562^{* * *}$ & $0.719^{* * *}$ & - \\
\hline 13 & $\begin{array}{l}\text { Overall emotional } \\
\text { intelligence }\end{array}$ & $0.784^{* * *}$ & $0.666^{* * *}$ & $0.895^{* * *}$ & $0.869^{* * * *}$ & $0.915^{* * *}$ & $0.323^{* *}$ & $0.332^{* *}$ & $0.292^{*}$ & $-0.247^{*}$ & $0.870^{* * * *}$ & $0.900^{* * * *}$ & $0.850^{* * *}$ \\
\hline
\end{tabular}

${ }^{*} \mathrm{p}<0.05,{ }^{* *} \mathrm{p} \leq 0.01,{ }^{* * *} \mathrm{p} \leq 0.001$

Significant correlations were found between the SSREIT and ESES scales and all their subscales at the beginning and the end of the semester. However, the correlations of empathetic concern (a subscale of IRI) with the SSREIT and ESES scales at the beginning and at the end of the semester differed. At the beginning of the course, significant correlations were found between fantasy and all the ESES subscales, with the exception of perceiving emotions, and all the SSREIT scales. At the end of course, no significant correlation was found between fantasy and regulation of emotions. Similarly, at the beginning of course, significant correlations were found between empathic concern and all SSREIT and ESES subscales, but at the end of course no correlations were found with understanding emotions (an ESES subscale) or with utilization or regulation of emotions (SSREIT subscales).

In addition, although perspective taking was significantly correlated with management of emotions, the overall ESES scale, and all SSREIT subscales at the beginning of the course, at the end of course it was no longer correlated with expression of emotions and regulation of emotions (SSREIT subscales), but was significantly correlated with management of emotions, the overall ESES scale, and all the other SSREIT subscales, as well as understanding emotions (an ESES subscale). Finally, at the beginning of course, personal distress was found to correlate negatively with understanding emotions (ESES) and utilization of emotions (SSREIT), and at the end of the course, it was negatively correlated with perceiving emotions (ESES), regulation of emotions, and the overall EI subscale.

These findings suggest that despite the strong correlations among the SSREIT and ESES subscales, they are related to empathy in different ways.

\section{Discussion}

Teachers in institutions of higher education face an enormous challenge of preparing students to tackle the complex realities they will face in their professional practice. Emotional intelligence has been found to be a significant contributor to professionals' knowledge and practice (Boyatzis, 2006; Daus \& Ashkanasy, 2005). However, despite its potential relevance for teaching practice, there have been little investigation and few reports about its application in educational settings or teachers' education (Low \& Nelson,2005).

The purpose of the present study was to contribute to the emerging literature on improvement of social emotional competencies in the academic training of future educators. The main objective was to examine the effects of an academic course, Emotional Intelligence in Education, on students' social emotional competencies as measured by emotional intelligence, empathy, and emotional self- efficacy. In addition, we examined the relationships between the three scales before and after the course.

Overall, the findings indicated an increase among the students who took the course in the degree of emotional intelligence and emotional self-efficacy from the beginning to the end of course (with the exception of management of emotion). Contrary to expectations, no increase was indicated in the empathy (as measured by the IRI scale) of the students who were enrolled in the course did not increase from the beginning to the end of the course, but their level of personal distress decreased.

The students in the control group displayed a decrease in all subscales. 
We also found partial correlations between the SSREIT, ESES, and IRI scales, but marked differences in the pattern of inter-correlations between the two time measurements (beginning and end of course).

These findings support other studies that have examined the contributions of EI training programs and courses in higher education to business people's level of work performance, to levels of emotion identification and emotion management abilities of health professionals (Fletcher, Leadbetter, Curran, \& O'Sullivan, 2009; Nelis, Quoidbach, Mikolajczak, \& Hansenne, 2009). They are also consistent with Jaeger's (2003) findings, and suggest that EI can be improved in higher education settings, highlighting the need to explore specific teaching strategies for this purpose (Low \& Nelson, 2005). The course examined in the present study employed an experiential teaching mode, based on the argument that teaching emotions and emotional management should be done in a creative and experiential manner (Low and Nelson, 2005; Weis \& Arnesen, 2007). Interestingly, in our study the subscales that improved the most at the end of course in the intervention group were those of personal distress - a significant decline (empathy) and regulation and utilization of emotions (emotional self-efficacy). This suggests that EI courses in higher education can provide a beneficial environment for students to not only express their emotions, but also use them for achieving their academic and interpersonal goals. Nevertheless this hypothesis requires further exploration in future research.

The overall empathy scores of the students did not change during the semester for either the intervention or the control group, thus failing to confirm our hypothesis and the view of other researchers that higher emotional intelligence generates higher levels of empathy (Brackett \& Katulak, 2007; Constantine \& Gainor, 2001). It may also be that although empathy is often viewed as a component of emotional intelligence (Brackett \& Mayer, 2003), they are actually two separate constructs. Accordingly, to enhance the empathy of students, it may be necessary to provide a longer course and/or include training in communication skills directed specifically towards developing empathy (Bonvicini et al., 2009).

Further examination of the four empathy subscales revealed a significant decrease in personal distress in the intervention group, suggesting that the greatest impact of teaching EI at this initial stage of professional development is the relief of personal distress. This finding is consistent with the results of Shoffner's (2009) study on pre-service teacher preparation, which suggested that addressing the affective domain early in training allows students to encounter their feelings and deal better with personal concerns.

An additional purpose of this study was to examine the relationship between emotional intelligence, emotional self-efficacy, and empathy. The inter-correlations found at the beginning of the course yielded a general pattern of significant positive correlations between all SSTREIT and ESES subscales, and significant correlations of some of these subscales with empathy subscales.

Comparison of the inter-correlations at the beginning and end of the course indicated that the increase in emotional intelligence and emotional self-efficacy accompanied in weaker or insignificant correlations with empathic concern and stronger significant correlations with perspective taking for emotional self-efficacy and the other way around for emotional intelligence. These findings suggest that overall emotional intelligence, emotional self-efficacy, and empathy are significantly inter-correlated, but the different emotional and cognitive components of each construct changed from the beginning to the end of course in unique and different patterns. It may indicate that emotional self-efficacy is a measurement of the cognitive components of empathy, but emotional intelligence refers to the emotional constituents of empathy. In a review of studies on empathy in the medical practice, Neumann et al. (2009) found that personal distress and sympathy correlated with an affective reaction, but perspective taking was associated with self-efficacy.

\section{Conclusions}

Empirical research has produced evidence that emotional competencies are important to the performance of educators. However, very little research has examined the effect of academic courses focused on emotional intelligence that are designed for teachers and other education providers. This study makes a contribution in this respect by examining whether and how an academic course that utilizes experiential teaching methods and focuses on developing emotional competencies promotes the social-emotional competencies of undergraduate students of education. The findings also suggest that an increase in emotional intelligence does not generate an increase in empathy, emphasizing the need for further study of the relationship between emotional intelligence and empathy.

The main limitation of the study is that it did not focus on evaluation of the course and its process, but only on a quantitative assessment of its contribution, thus limiting the information gathered and the ability to generalize the findings for other programs. In addition, although a control group was used, the sample was relatively small and the groups were not randomly assigned, which may be deleterious to the experimental design. In order to reduce the 
possibility of bias, we compared the two groups in terms of both demographic characteristics and the experimental variables. Future research should employ qualitative instruments to learn more about the development of both emotional intelligence and empathy among education professionals, and further study how the teaching strategies utilized in this course can be adapted and applied in other higher education settings.

\section{References}

Archer, W., \& Davison, J. (2008). Graduate employability: What do employers think and want? London, UK: Council for Industry and Higher Education. Retrieved from $\mathrm{http}: / /$ ec.europa.eu/education/higher-education/doc/business/graduate_en. pdf

Bandura, A. (1997). Self-efficacy: The exercise of control. New York: Freeman.

Bandura, A. (2001). Social cognitive theory: An agentic perspective. Annual Review of Psychology, 52(1), 1-26. http://dx.doi.org/10.1146/annurev.psych.52.1.1

Bonvicini, K. A., Perlin, M. J., Bylund, C. L., Carroll, G., Rouse, R. A. \& Goldstein, M. G. (2009) Impact of communication training on physician expression of empathy in patient encounters. Patient Education and Counseling, 75(1), 3-10. http://dx.doi.org/10.1016/j.pec.2008.09.007

Boyatzis, R. (2006). Using tipping points of emotional intelligence and cognitive competencies to predict financial performance of leaders. Psicothema, 18, 124-131.

Brackett, M. A. \& Mayer, J. D. (2003) Convergent, discriminant, and incremental validity of competing measures of emotional intelligence. Personality and Social Psychology Bulletin, 29(9), 1147. http://dx.doi.org/10.1177/0146167203254596

Brackett, M. A., \& Katulak, N. A. (2007). Emotional intelligence in the classroom: skill-based training for teachers and students. In J. Ciarrochi and J. D. Mayer (eds), Applying emotional intelligence: A practitioner's guide (pp. 1-27). New York, NY: Psychology Press.

Brackett, M. A., Rivers, S. E., Shiffman, S., Lerner, N., \& Salovey, P. (2006). Relating emotional abilities to social functioning: a comparison of self-report and performance measures of emotional intelligence. Journal of personality and social psychology, 91(4), 780. http://dx.doi.org/10.1037/0022-3514.91.4.780

Brown, P., Hesketh, A., \& Williams, S. (2002). Employability in knowledge-driven economy. Working Paper 26, School of Social Sciences, Cardiff University [posted on department website]. Retrieved from http://www.cf.ac.uk/socsi/ publications/workingpapers/ > Papers $21-30$.

Brown, R. B. (2003). Emotions and behavior: Exercises in emotional intelligence. Journal of Management Education, 27(1), 122-144. http://dx.doi.org/10.1177/1052562902239251

Carson, R. L., III (2006). Exploring the episodic nature of teachers' emotions as it relates to teacher burnout. Doctoral dissertation. Available from ProQuest database (1216740561).

Chan, D. W. (2004). Perceived emotional intelligence and self-efficacy among Chinese secondary school teachers in Hong Kong. Personality and Individual Differences, 36, 1781-1795. http://dx.doi.org/10.1016/j.paid.2003.07.007

Chan, D.W. (2006). Emotional intelligence and components of burnout among Chinese secondary school teachers in Hong Kong. Teaching and Teacher Education, 22(8), 1042-1054. http://dx.doi.org/10.1016/j.tate.2006.04.005

Cherniss, C., Goleman, D., Emmerling, R., Cowan, K., \& Adler, M. (1998). Bringing emotional intelligence to the workplace. Technical report issued by Consortium for Research on Emotional Intelligence in Organizations, Rutgers University, New Brunswick, NJ. Available online at: http://www.eiconsortium.org/reports/ technical_report.html, accessed July 19, 2011.

Clark, S. C., Callister, R., \& Wallace, R. (2003). Undergraduate management skills courses and students' emotional intelligence. Journal of Management Education, 27(1), 3-23. http://dx.doi.org/10.1177/1052562902239246

Constantine, M. G., \& Gainor, K. A. (2001). Emotional intelligence and empathy: their relation to multicultural counseling knowledge and awareness. Professional School Counseling, 5(2), 131-137.

Danielsen, R., \& Cawley, J. (2007). Compassion and integrity in health professions education. Journal of Allied Health Science and Practice, 5(2), 1-9.

Daus, C. S., \& Ashkanasy, N. M. (2005). The case for the ability-based model of emotional intelligence in organizational behavior. Journal of Organizational Behavior, 26, 453-466. http://dx.doi.org/10.1002/job.321 
Davis, M. (1980). A multidimensional approach to individual differences in empathy. JSAS Catalogue of Selected Documents in Psychology, 10, 85.

Elias, M. J. (2006). The connection between academic and social emotional learning. In M.J. Elias \& H. Arnold (eds.) The educators guide to emotional intelligence and academic achievement (pp. 4-14). Thousand Oaks, CA: Corwin Press.

Elias, M. J. (2009). Social-emotional and character development and academics as a dual focus of educational policy. Educational Policy, 23(6), 831-846. http://dx.doi.org/10.1177/0895904808330167

Emmer, E. T. (1994). Classroom management for secondary teachers. Needham Heights, MA: Allyn and Bacon.

Emmer, E. T. \& Stough, L. M. (2001). Classroom management: A critical part of educational psychology, with implications for teacher education. Educational Psychologist, 36(2), 103-112. http://dx.doi.org/10.1207/S15326985EP3602_5

Ergur, D.O. (2009). How can education professionals become emotionally intelligent? Prcocedia - Social and Behavioral Sciences, 1(1), 1023-1028. doi.org/10.1016/j.sbspro.2009.01.183

Fernandez-Berrocal, P., \& Ruiz, D. (2008). Emotional intelligence in education. The Electronic Journal of Research in Educational Psychology, 15(6), 421-436.

Fletcher, I., Leadbetter, P., Curran, A., O'Sullivan, H. (2009). A pilot study assessing emotional intelligence training and communication skills with 3rd year medical students. Patient Education and Counseling 76, 376-379. http://dx.doi.org/10.1016/j.pec.2009.07.019

Fredrickson, B. L. (2001). The role of positive emotions in positive psychology. American Psychologist, 56(3), 218-226. http://dx.doi.org/10.1037/0003-066X.56.3.218

Goleman, D. (1995). Emotional intelligence. New York, NY: Bantam.

Hargreaves, A. (1998). The emotional politics of teaching and teacher development: With implications for educational leadership. International Journal of Leadership in Education, 1(4), 315-336. http://dx.doi.org/10.1080/1360312980010401

Hen, M. (2010). Mesugalut atsmit ve'empatya bekerev morim meshalvim [Self-efficacy and empathy among inclusive teachers]. Ma' of Uma'aseh, 13, 134-165.

Jaeger, A. J. (2003). Job competencies and the curriculum: an inquiry into emotional intelligence in graduate professional education. Research in Higher Education, 44(6), 615-639. http://dx.doi.org/10.1023/A:1026119724265

Jennings, P. A., \& Greenberg, M. T. (2009). The prosocial classroom: Teacher social and emotional competence in relation to student and classroom outcomes. Review of Educational Research, 79(1), 491. http://dx.doi.org/10.3102/0034654308325693

Kirk, B. A., Schutte, N. S., \& Hine, D. W. (2008). Development and preliminary validation of an emotional self-efficacy scale. Personality and Individual Differences, 45(5), 432-436. http://dx.doi.org/10.1016/j.paid.2008.06.010

Lopes, P. N., Salovey, P., Côté, S., Beers, M., \& Petty, R. E. (2005). Emotion regulation abilities and the quality of social interaction. Emotion, 5(1), 113. http://dx.doi.org/10.1037/1528-3542.5.1.113

Louie, A. K., Coverdale, J., \& Roberts, L. W. (2006). Emotional intelligence and psychiatric training. Academic Psychiatry, 30(1), 1. http://dx.doi.org/10.1176/appi.ap.30.1.1

Low, G., \& Nelson, D. (2005). Emotional intelligence: the role of transformative learning in academic excellence. Texas Study of Secondary Education, 15(2), 41-44.

Low, G., Nelson, D., Stottlemyer, B. \& Davenport, E. (2000). The emotionally intelligent teacher. Paper presented at the Fourth Annual Conference on School-University Partnerships, Texas A\&M University System and The Texas Education Agency, Austin, TX.

Mayer, J. D. Roberts, R,D., \& Barsade, S.G. (2008). Human Intelligence. Annual Review of Psychology, 59, 507-536. http://dx.doi.org/10.1146/annurev.psych.59.103006.093646

Mayer, J. D., \& Salovey, P. (1997). What is emotional intelligence? In P. S. Salovey, and D. J. Mayer (eds.), Emotional development and emotional intelligence (pp. 3-31). New York, NY: Basic Books. 
Mayer, J. D., Salovey, P., \& Caruso, D. (2004). Models of emotional intelligence. In P. Salovey, M. A. Brackett \& J. H. Mayer (eds), Emotional intelligence: Key Readings on the Mayer and Salovey Model (pp. 81-121, 162). New York, NY: National Professional Resources Inc.

McEnrue, M. P., Groves, K. S., \& Shen, W. (2010). Emotional intelligence training: Evidence regarding its efficacy for developing leaders. Kravis Leadership Institute, Leadership Review, 10, 3-26.

Montgomery, C., \& Rupp, A. A. (2005). A meta-analysis for exploring the diverse causes and effects of stress in teachers. Canadian Journal of Education/Revue Canadienne De l'Education, 28(3), 458-486. http://dx.doi.org/10.2307/4126479

Mortiboys, A. (2005). Teaching with emotional intelligence. Abingdon Oxon: Routledge.

Nelis, D., Quoidbach, J., Mikolajczak, M., \& Hansenne, M. (2009). Increasing emotional intelligence: (How) is it possible? Personality and Individual Differences, 47, 36-41. http://dx.doi.org/10.1016/j.paid.2009.01.046

Neumann, M., Bensing, J., Mercer, S., Ernstmann, N., Ommen, O., \& Pfaff, H. (2009). Analyzing the 'nature' and 'specific effectiveness' of clinical empathy: A theoretical overview and contribution towards a theory-based research agenda. Patient Education and Counseling, 74(3), 339-346. http://dx.doi.org/10.1016/j.pec.2008.11.013

Opengart, R. (2007). Integrative literature review: Emotional intelligence in the K-12 curriculum and its relationship to American workplace needs. Human Resource Development Review, 6, 442-458. http://dx.doi.org/10.1177/1534484307307556

Pianta, R. C., \& La Paro, K. (2003). Improving early school success. Educational Leadership, 60(7), 24-29.

Ragozzino, K., Resnik, H., Utne-O Brien, M., \& Weissberg, R. P. (2003). Promoting academic achievement through social and emotional learning. Educational Horizons, 81, 169-171.

Salovey, P., \& Mayer, J. D. (1990). Emotional intelligence. Children, 5, 185.

Schutte, N. S., Malouff, J. M., Hall, L. E., Haggerty, D. J., Cooper, J. T., Golden, C. J., \& Dornheim, L. (1998). Development and validation of a measure of emotional intelligence. Personality and Individual Differences, 25(2), 167-177. http://dx.doi.org/10.1016/S0191-8869(98)00001-4

Shoffner, M. (2009). The place of the personal: Exploring the affective domain through reflection in teacher preparation. Teaching and Teacher Education, 25(6), 783-789. http://dx.doi.org/10.1016/j.tate.2008.11.012

Sutton, R. E., \& Wheatley, K. F. (2003). Teachers' emotions and teaching: A review of the literature and directions for future research. Educational Psychology Review, 15(4), 327-358. http://dx.doi.org/10.1023/A:1026131715856

Walter, O. \% Hen, M. (2009). Movement and emotional intelligence in higher education. The International Journal of Learning 16, 8-34.

Weare, K., \& Gray, G. (2003). What works in developing children's emotional and social competence and wellbeing? Available online at: http://www.dfes.gov.uk/ research/data/uploadfiles/RR456.doc

Webster-Stratton, C.H., \& Reid, M.J. (2011). Combining parent and child training for young children with ADHD. Journal of Clinical Child \& Adolescent Psychology, 40(2), 191-203. http://dx.doi.org/10.1080/15374416.2011.546044

Webster-Stratton, C., Reid, M. J. and Stoolmiller, M. (2008). Preventing conduct problems and improving school readiness: Evaluation of the incredible years teacher and child training programs in high-risk schools. Journal of Child, 39, 1469-7610. http://dx.doi.org/10.1111/j.1469-7610.2007.01861.x

Weis, W.L., \& Arnesen, D.W. (2007). Because EQ can't be told: Doing something about emotional intelligence. Journal of Organizational Culture, Communications and Conflict, 11(2), 113-123. 